\title{
TECNOLOGIAS DE INFORMAÇÃO E COMUNICAÇÃO: INTERESSES E EXPECTATIVAS DE ESTUDANTES
}

\author{
Humberto Celeste Innarelli \\ Vanda de Fátima Fulgêncio de Oliveira
}

\begin{abstract}
RESUMO
Este artigo apresenta os resultados de um levantamento empírico sobre o impacto das tecnologias da informação e comunicação (TIC) sobre a realidade de um grupo de estudantes. Foram analisados sujeitos de diferentes faixas etárias, grau de instrução, níveis socioeconômicos e sexos; oriundos de uma universidade particular de ensino superior, alunos de uma escola técnica de informática e alunos de uma escola situada na área rural. O procedimento de coleta de dados foi feito através de questionários aplicados aos sujeitos da pesquisa. $\mathrm{Na}$ análise, os estudantes foram caracterizados em grupos em relação ao grau de instrução, idade, sexo, utilização e frequiência de uso do computador, tempo de uso do computador, para quê usa o computador, quais os softwares e sistemas operacionais mais utilizados e a forma de uso das bibliotecas. Em seguida foi realizada uma análise envolvendo todos os estudantes dentro dos seguintes agrupamentos: Urbano versus Rural; Uso do Computador versus Pesquisa; Otimistas versus Pessimistas e Software versus Utilização. Como resultados e conclusões, apresentamos as expectativas e significados atribuídos pelos estudantes para a Sociedade da Informação e os contornos sociais e econômicos que os envolvem.
\end{abstract}

\section{PALAVRAS-CHAVE}

Sociedade da Informação; Tecnologia da Informação; Mudança Social; Pesquisa; Estudantes.

\begin{abstract}
This article presents the results of an empirical survey on the impact of the information technologies on the reality of a students group. This work analyzed people of different ages, instruction degrees and social and economic levels; resulting from a particular university, a computer science technical school and a school situated in the country area. The procedure of collecting data was made through questionnaires applied to the pupils of the university and the schools. In this analysis, the students had been characterized in relation to the instruction degree, age, sex and frequency of using the computer. Other aspects were observed too, such as time of using the computer, reason of using the computer, definition of software and operational systems more used and the systems used in the libraries. For questionnaire analysis, we divided the students in to groups facing an Urban and a Country group, the Use of Computer and Research, Optimists and Pessimists and Software and Use. After this analyses we are presenting the expectative and the meaning attributed for the students to the Information Society and the related social and economic aspects.
\end{abstract}

\section{KEY WORDS}

Information Society; Information Technology; Social Change; Research; Students.

(C) ETD - Educação Temática Digital, Campinas, v.5, n.1, p.49-63, dez. 2003 - ISSN: 1517-2539. 


\section{INTRODUÇÃO}

Este artigo tem como finalidade apresentar os resultados de um levantamento empírico referente ao impacto das tecnologias da informação e comunicação (TIC) sobre a realidade de um grupo de estudantes e, de forma mais precisa, seus interesses e expectativas em relação ao que hoje chamamos de "Sociedade da Informação".

As tecnologias de informação e comunicação e seus impactos na educação, saúde, organizações sociais e políticas, ciências e artes são tema de uma multiplicidade de artigos científicos, dissertações, teses e livros publicados recentemente nas mais variadas áreas do conhecimento.

Embora alguns autores proponham que os processos de mudanças sociais no universo das organizações devam ser analisados empiricamente, há ainda carência de pesquisas empíricas sobre o tema.

As análises não são convergentes e não há consenso sobre as mudanças sociais, econômicas e políticas que estão sendo causadas pelo impacto das TIC na sociedade. $\mathrm{O}$ certo é que o desenvolvimento contínuo das TIC produz um intenso fluxo de informação, influenciando inclusive o fazer "teórico" e "filosófico" sobre o tema.

Segundo Waldman e Yacoub (2000), ainda não sabemos quais são os novos produtos que impulsionarão as ondas de consumo da terceira revolução industrial. Mas parece claro que estes produtos serão imateriais: ao invés do aço e do plástico, eles serão feitos de informação e cultura; o valor não é mais agregado ao bem material e sim à informação.
Atualmente temos tecnologias como o GED1 e o Workflow2 O GED, citado por Avedon (1999), é uma tecnologia capaz de gerenciar de forma eletrônica qualquer tipo de documento, seja ele eletrônico ou não. Já Workflow, segundo Cruz (1998), é definido como a automação de fluxos de trabalho, ou seja, um recurso que possibilita automatizar processos, racionalizando-os e potencializando-os por meio de dois componentes implícitos: organização e tecnologia. Esta tecnologia, além de otimizar e informatizar o fluxo de trabalho, possibilita economia de material e de tempo, podendo ainda gerar documentos eletrônicos, que circularão e poderão ser armazenados em diversos tipos de mídias digitais.

A nova sociedade informacional pode ser entendida como uma economia centrada na informação, que teve seu início no período pós-guerra (entre 1945-1970), época em que o computador começou a ser usado intensivamente em grandes projetos, como a defesa nacional e a exploração espacial. Os Estados Unidos lideraram este estágio, incentivando as descobertas tecnológicas em microeletrônica, computadores e telecomunicações, e acelerando o que podemos denominar de Revolução da Tecnologia da Informação.

Nos anos 70, segundo Lévy (1999, p.31), o desenvolvimento e a comercialização do microprocessador (unidade de cálculo aritmético e lógico localizada em um pequeno chip eletrônico) dispararam diversos processos econômicos e sociais de grande extensão, abrindo uma nova fase na automação da produção industrial: robótica, linhas de produção flexíveis, máquinas industriais com controle digitais e também o princípio da automação de alguns setores do terciário (bancos, seguradoras). Por outro

${ }^{1}$ Gerenciamento Eletrônico de Documentos.

${ }^{2}$ Fluxo de Trabalho Automatizado. 
lado, segundo o autor, "um verdadeiro movimento social nascido na Califórnia na efervescência da 'contracultura' apossou-se das novas possibilidades técnicas e inventou o computador pessoal" (LÉVY, 1999, p. 31).

Essas iniciativas possibilitaram a popularização do computador, que deixou de estar exclusivamente subordinado aos serviços de processamento de dados das grandes empresas e dos programadores profissionais para tornar-se um poderoso instrumento de criação (de textos, de imagens, de músicas), de organização (bancos de dados, planilhas), de simulação (planilhas, ferramentas de apoio à decisão, programas para pesquisa) e de diversão (jogos), comunicação e negócios.

Nesse sentido, de acordo com Lévy (1999, p.32), nos anos 80 a informática perdeu, pouco a pouco, seu status de técnica e de setor industrial particular para começar a fundir-se com as telecomunicações, a editoração, o cinema e a televisão. Novas formas de mensagens "interativas" apareceram: videogames, interfaces gráficas e interações sensório-motoras e o surgimento dos hiperdocumentos.

No final dos anos 80 e início dos anos 90 as diferentes redes de computadores formadas desde o final dos anos 70, juntaram-se umas às outras e o número de pessoas e de computadores conectados à inter-rede começou a crescer de forma exponencial, expandindo o que hoje é conhecido como internet (rede internacional).

Como no caso da invenção do computador pessoal, uma corrente cultural espontânea e imprevisível impôs um novo curso ao desenvolvimento tecno-econômico. As tecnologias digitais surgiram, então, como a infra-estrutura do ciberespaço, um novo espaço de comunicação, de sociabilidade, de organização e de transação, mas também novo mercado da informação e do conhecimento (LÉVY, 1999, p. 32).

Segundo Castells (1999, p.78) os aspectos centrais do paradigma da tecnologia da informação, que são a base material da sociedade da informação, são os seguintes:

A primeira característica do novo paradigma é que a informação é sua matéria-prima: são tecnologias para agir sobre a informação, não apenas informação para agir sobre a tecnologia.

$\mathrm{O}$ segundo aspecto refere-se à penetrabilidade dos efeitos das novas tecnologias. Como a informação é uma parte integral de toda atividade humana, todos os processos de nossa existência individual e coletiva são diretamente influenciados pelos novos recursos tecnológicos.

A terceira característica refere-se à lógica de redes em qualquer sistema ou conjunto de relações. Uma rede pode ser implementada materialmente em todos os tipos de processos e organizações, graças às recentes tecnologias da informação.

Em quarto lugar, referente ao sistema de redes, mas sendo um aspecto claramente distinto, o paradigma da tecnologia da informação é baseado na flexibilidade. $\mathrm{O}$ que distingue a configuração do novo paradigma tecnológico é sua capacidade de adaptação, um aspecto decisivo em uma sociedade caracterizada por constante mudança e fluidez organizacional.

E uma quinta característica dessa revolução tecnológica é a crescente conver-gência de tecnologias específicas para sistemas altamente integrados, nos quais trajetórias tecnológicas antigas ficam literalmente impossíveis de se distinguir em separado.

No Brasil, o Ministério da Ciência e da Tecnologia preparou um "livro verde" para 
nortear e dar parâmetros para o desenvolvimento da Sociedade da Informação:

A sociedade da informação não é um modismo. Representa uma profunda mudança na organização da sociedade e da economia, havendo quem a considere um novo paradigma técnico-econômico. É um fenômeno global, (...) Sua importância assemelha-se à de uma boa estrada de rodagem para o sucesso econômico das localidades. Tem ainda marcante dimensão social, em virtude do seu elevado potencial de promover a integração, ao reduzir as distâncias entre pessoas e aumentar o seu nível de informação (TAKAHASHI, 2000. p. 5.).

Muitas questões se colocam hoje em relação às tecnologias de informação. Temos a intensiva publicidade de seus fabricantes e vendedores, os discursos dos "otimistas" e a contrapartida dos "pessimistas'. Temos também o uso efetivo que é feito das tecnologias por diferentes sujeitos sociais em seus contextos diários: em casa, no trabalho, nas escolas e na atividades sociais de uma forma mais ampla, seja nas áreas urbanas ou rurais.

De que forma as pessoas utilizam as tecnologias? Como esse uso traz transformações e mudanças de comportamento e atitude? Como a sociedade incorpora as tecnologias em sua prática? Quais mudanças de atitudes advêm dessa assimilação, e como se "criam" expectativas otimistas e pessimistas em relação ao crescente avanço das tecnologias em todas as áreas da vida social? São questões em aberto. Tentamos uma primeira aproximação neste campo através desta pesquisa, procurando caracterizar e levantar alguns números sobre um grupo de estudantes usuários de tecnologias de informação.

\section{A PESQUISA EMPÍRICA}

Realizamos esta pesquisa com alunos de três níveis: a) de ensino superior (universidade particular); b) de uma escola técnica de informática e c) de uma escola situada na área rural, com o objetivo de identificar a utilização das tecnologias de informação por sujeitos de diferentes faixas etárias, grau de instrução, níveis socioeconômicos e sexos. Buscou-se ainda oferecer subsídios para uma melhor compreensão das expectativas dos sujeitos em relação às transformações da sociedade trazidas pelas novas tecnologias da informação e identificar o "significado" da palavra informação pelos diferentes sujeitos pesquisados.

A opção pela instituição de ensino foi feita pela familiaridade que os pesquisadores tinham com cada realidade e também pela diversidade social dos sujeitos que as três escolas comportam.

A coleta de dados foi realizada por questionários aplicados aos sujeitos da pesquisa, sendo cada questionário composto por 17 questões de múltipla escolha e duas questões abertas. Alguns questionários iniciais foram aplicados como pré-teste nas escolas selecionadas. Após o primeiro préteste o questionário foi reelaborado $\mathrm{e}$ respondido por 50 alunos da instituição de ensino superior, 50 alunos da escola técnica de informática e 48 alunos da escola de ensino fundamental da área rural.

Os dados foram coletados nas três instituições durante a primeira semana de novembro de 2002; os questionários foram aplicados em sala de aula por professores.

Foi perguntado há quanto tempo fazem uso do computador e qual a freqüência de uso: na escola, no trabalho e em casa, bem como o uso feito do computador e quais os softwares utilizados. 
Tentamos "mapear" um pouco as transformações que as Tecnologias da Informação trouxeram à humanidade ou ao indivíduo em questões como: democratização da Informação; acesso à informação restrito a uma "elite" de pessoas; globalização das informação; controle da informação; facilidade $e$ dificuldades de acesso à informação; interatividade e possibilidade de expressão; banalização da informação; desemprego e criação de novos postos de trabalho; exigências de maior qualificação de profissionais; maior ou menor comunicação entre as pessoas, e ainda uma questão sobre o aumento ou diminuição da "solidariedade" entre as pessoas.

A relação entre o aumento do uso de tecnologias de informação e $\mathrm{o}$ uso simultâneo da Biblioteca Escolar ou Universitária foi uma das preocupações da pesquisa. Nosso principal questionamento em relação à biblioteca foi: quais são os usos de tecnologias da informação nas bibliotecas no contexto de modernização e informatização destas?

Para responder a estas perguntas, levantamos questões como: a biblioteca é utilizada? A biblioteca é informatizada? Como é utilizada a biblioteca? E também perguntas sobre pesquisas na Internet, em bases de dados especializadas e o levantamento de livros no catálogo bibliográfico on-line .

As questões abertas foram as seguintes: "Você tem projetos futuros de trabalhar na área de informática?" e "O que significa informação para você?".

\section{ANÁLISE DOS DADOS}

$\mathrm{Na}$ análise dos dados da pesquisa tentamos "ouvir e sentir os números", como sugeriu o professor Tom Dwyer3. Como metodologia, utilizamos um primeiro agrupamento, dividindo os alunos em três grupos, por escolas. Nesta fase da análise caracterizamos os estudantes por grupo em relação a: grau de instrução, idade, sexo, utilização e frequiência de uso do computador, tempo de uso do computador, para que usa o computador, quais os softwares e sistemas operacionais mais utilizados e a utilização das bibliotecas.

Em uma segunda fase, realizamos uma análise mais global, envolvendo todos os estudantes dentro dos seguintes agrupamentos: Urbano versus Rural; Uso do Computador versus Pesquisa; Otimistas versus Pessimistas; e Software versus Utilização. Os quatro agrupamentos foram selecionados e considerados relevantes para a análise a partir da leitura dos questionários, da tabulação dos dados e da reflexão dos pesquisadores.

A seguir passaremos a descrever os primeiros agrupamentos que caracterizam os estudantes:

\section{ESTUDANTES TÉCNICOS}

Os estudantes da Escola Técnica de Informática estudam no período noturno, sendo $78 \%$ trabalhadores e $22 \%$ que não trabalham; $28 \%$ são do sexo feminino e $72 \%$ do sexo masculino; $22 \%$ são casados e $78 \%$ são solteiros. As idades dos estudantes da escola técnica de informática variam de 17 a 44 anos de idade.

Dos estudantes técnicos, $90 \%$ possuem o Ensino Médio Completo; 4\% Superior Incompleto; 2\% Ensino Fundamental

\footnotetext{
${ }^{3}$ Professor e Coordenador do Doutorado em Ciências Sociais da Universidade Estadual de Campinas (Unicamp)
} 
Completo; $2 \%$ Ensino Médio Incompleto e outros: $2 \%$.

Grau de instrução dos pais: $40 \%$ possuem Ensino Fundamental Incompleto; 22\% Ensino Médio Incompleto; 18\% Ensino Médio Completo; 12\% Ensino Fundamental Completo e 2\% Superior Incompleto.

\section{Utilização do computador e freqüência de uso}

Dos 50 estudantes entrevistados, 92\% disseram que utilizam computadores e $6 \%$ apenas disseram não utilizar.

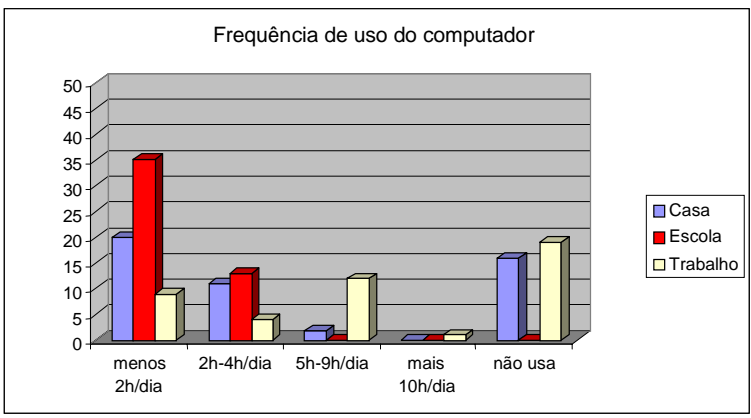

FIGURA 1 - Freqüência de uso do computador

Em relação à frequiência de utilização do computador, dividimos em três locais de uso: em casa, na escola e no trabalho. A quantidade de horas de utilização foi dividida em: menos de duas horas por dia, de duas a quatro horas por dia, de cinco a nove horas por dia e mais de dez horas por dia. Esse procedimento se repetirá nos dados sobre estudantes do ensino fundamental da área rural e estudantes universitários.

A categoria "uso em casa" teve como maior frequiência o uso de menos de duas horas por dia, seguido daqueles que não usam em casa e, em terceiro lugar, o uso de duas a quatro horas por dia e em último lugar o uso de cinco a nove horas por dia. Na categoria de "uso na escola" teve a maior frequiência o uso de menos de duas horas por dia; em seguida o uso de duas a quatro horas por dia. Na categoria de "uso no trabalho" teve maior freqüência a alternativa "não usa" e, em seguida, o uso de cinco a nove horas por dia. Esse índice se deve provavelmente ao fato de $22 \%$ dos estudantes não estarem trabalhando.

\section{Tempo de uso do computador e para que o utiliza}

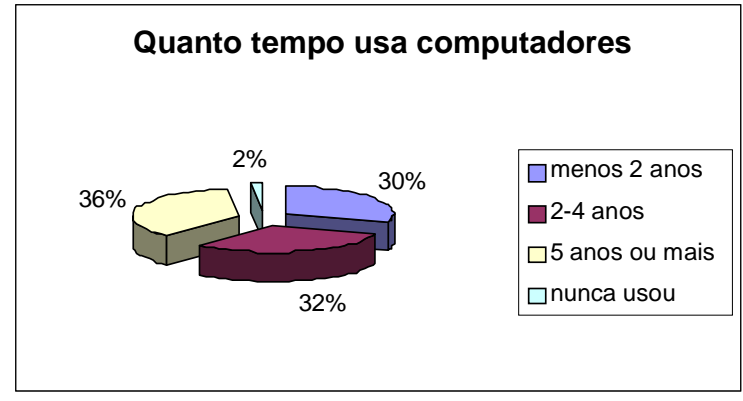

FIGURA 2 - Tempo de uso do computador

Dos entrevistados, $36 \%$ utilizam o computador há cinco anos ou mais; $32 \%$ o utilizam de dois a quatro anos e $0 \%$ utilizam há menos de dois anos.

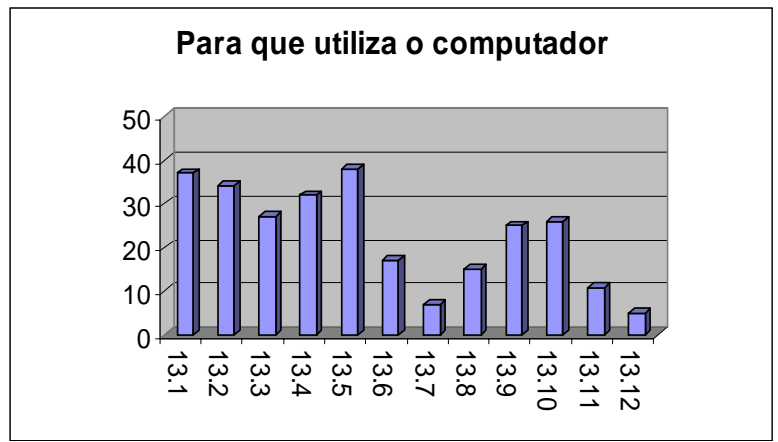

FIGURA 3 - Para que utiliza o computador

13.1 - Informação (leitura de jornais e revistas)

13.2 - Correio eletrônico (e-mail)

13.3 - Programação

13.4 - Redação/Editoração de textos

13.5 - Pesquisas na Internet

13.6 - Chats (Bate papo)

13.7 - Manutenção de bancos/bases de dados 
13.8 - Preparação/manutenção de planilhas eletrônicas

13.9 - Ouvir/gravar músicas

13.10 - Jogos

13.11 - Usuário de sistema especifico

13.12 - Outros

Em relação ao uso do computador, a maior freqüência é o uso para pesquisa na internet, seguida de informação (leitura de jornais e revistas), correio eletrônico e depois Redação/Editoração de textos. Apesar de serem estudantes de uma escola técnica de informática, o uso para programação aparece em quinto lugar.

\section{Softwares e sistemas operacionais mais utilizados}

Os softwares aplicativos e sistemas operacionais foram considerados da mesma forma como alternativas de softwares mais utilizados. Assim, o sistema operacional Windows aparece em primeiro lugar, seguido respectivamente pelo MS-Word e Internet Explorer.

\section{Os estudantes técnicos e o uso da Biblioteca}

Dos estudantes técnicos, $74 \%$ utilizam a biblioteca, enquanto que $26 \%$ não a utilizam; $12 \%$ disseram que a biblioteca é informatizada, e $88 \%$ disseram que a biblioteca não é informatizada. A maior freqüência para o uso da biblioteca foi para leitura de jornais e revistas, seguida de estudo de conteúdos indicados pelos professores e elaboração de trabalhos. Em quarto lugar aparece o empréstimo de livros e a pesquisa na internet aparece em quinto lugar. As alternativas "Levantamento de livros no catálogo bibliográfico" e "Conferir informações encontradas na Internet", embora sejam citadas, também têm baixa freqüência. Este fator pode estar ligado ao baixo número de estudantes que disseram que a biblioteca é informatizada ou ainda ao desconhecimento dos recursos oferecidos pelas mesmas. Por outro lado, podemos também questionar sobre como as bibliotecas oferecem seus recursos informatizados: horários de acesso, quantidade de computadores disponíveis, espaço para pesquisa na Internet $\mathrm{e}$ divulgação dos serviços.

\section{Estudantes do ensino fundamental da área rural}

$\mathrm{Na}$ escola rural de ensino fundamental, todos os alunos são estudantes do período diurno, sendo $8 \%$ trabalhadores e $92 \%$ que não trabalham. Do total, $42 \%$ são do sexo masculino e $58 \%$ feminino.

As idades dos estudantes da escola de ensino fundamental da área rural variam de 12 a 17 anos. Todos são solteiros e todos têm como grau de instrução o ensino fundamental incompleto.

Grau de instrução dos pais: $83 \%$ têm ensino fundamental incompleto; 9\% - ensino fundamental completo; $4 \%$ - ensino médio incompleto; $2 \%$ - superior incompleto; $2 \%$ superior completo.

\section{Utilização do computador e freqüiência de} uso

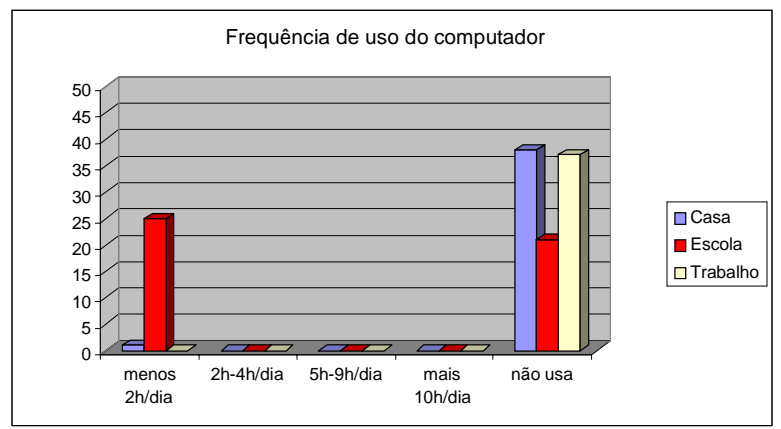

FIGURA 4 - Freqüência de uso computador

Dos 48 estudantes da escola fundamental da área rural entrevistados, $42 \%$ disseram que 
utilizam computadores e $58 \%$ disseram não utilizar.

A categoria "uso em casa" teve como maior freqüência a resposta "não uso", sendo que apenas dois estudantes afirmaram usar em casa. Embora 8\% dos estudantes estejam trabalhando, nenhum deles afirmou utilizar computadores no trabalho. A maior freqüência é o uso na escola, na categoria de menos de duas horas por dia.

\section{Tempo de uso do computador e para que o utiliza}

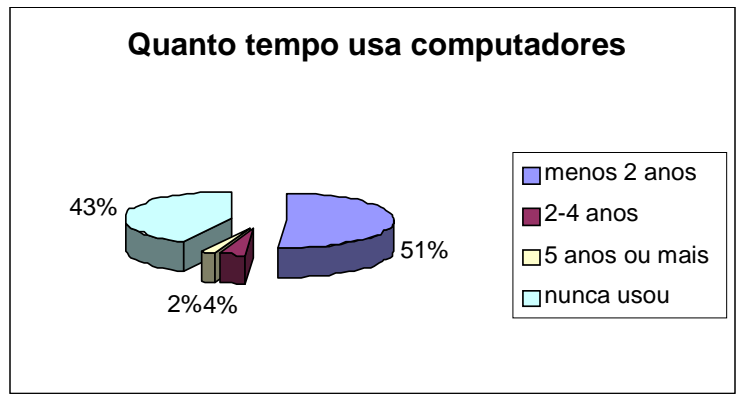

FIGURA 5 - Tempo de uso do computador

Dos alunos entrevistados, $51 \%$ utilizam o computador há menos de dois anos; $43 \%$ nunca utilizaram computadores; $4 \%$ utilizam de dois e quatro anos e apenas $2 \%$ utilizam há cinco anos ou mais.

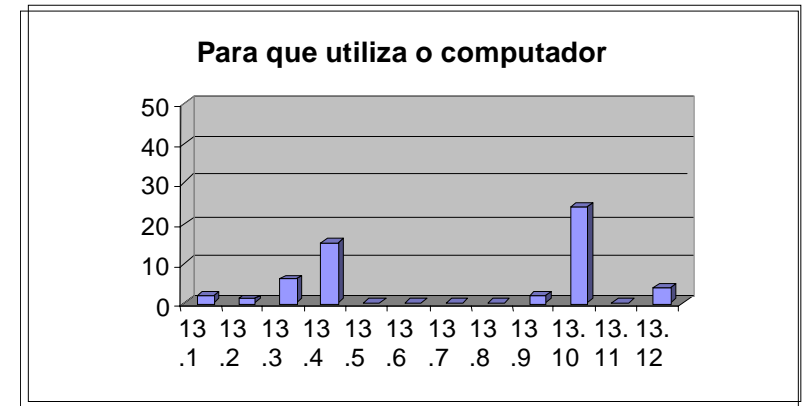

FIGURA 6 - Para que utiliza o computador

13.1 - Informação (jornais e revistas)

13.2 - Correio eletrônico (e-mail)

13.3 - Programação

13.4 - Redação/Editoração de textos 13.5 - Pesquisas na Internet
13.6 - Chats (Bate papo)

13.7 - Manutenção de bancos/bases de dados

13.8 - Preparar/manut. de plan. eletrônicas

13.9 - Ouvir/gravar músicas

13.10 - Jogos

13.11 - Usuário de sistema especifico

13.12 - Outros

Em relação ao uso do computador, a maior freqüência é para jogos, seguido de Redação/ Editoração de textos. Como a maior frequiência é o uso na escola, sendo que na mesma não há acesso à Internet, o uso de email, navegação em sites, ouvir/gravar músicas foram alternativas somente aos estudantes que utilizam computador em casa, ou seja, apenas dois.

\section{Softwares e sistemas operacionais mais utilizados}

Os softwares e sistemas operacionais foram considerados da mesma forma como alternativas de softwares mais utilizados. $\mathrm{O}$ sistema operacional Windows aparece em primeiro lugar, seguido respectivamente pelo uso de jogos e MS-Word.

\section{Os estudantes da escola rural e o uso da Biblioteca}

Dos estudantes do ensino fundamental, $100 \%$ utilizam a biblioteca; $13 \%$ disseram que a biblioteca é informatizada, enquanto $87 \%$ disseram que a biblioteca não é informatizada.

A maior freqüência para o uso da biblioteca foi para elaboração de trabalhos, seguida de empréstimos de livros. Em terceiro lugar, o estudo de conteúdos indicados pelos professores e em quarto lugar a leitura de jornais e revistas. Embora 13\% dos alunos da escola rural tenham dito que a biblioteca é informatizada, este fato parece não corresponder à realidade, visto que as 
perguntas sobre a pesquisa na Internet e em bases de dados especializadas e ainda o levantamento de livros no catálogo bibliográfico on-line não tiveram nenhuma resposta. Parece relevante o fato de todos os estudantes frequientarem a biblioteca. Isso pode ser atribuído a ser essa a única fonte de informação que possuem, ou talvez a algum trabalho de conscientização dos professores quanto à importância do uso da mesma.

\section{ESTUDANTES UNIVERSITÁRIOS}

Os universitários são estudantes do período noturno; 94\% são trabalhadores e apenas 8\% não trabalham; $18 \%$ são do sexo feminino e $82 \%$ do sexo masculino; $18 \%$ são casados e $82 \%$ são solteiros; $99 \%$ são estudantes com grau de instrução superior incompleto e apenas um já possui curso superior. A idade dos estudantes universitários varia de 18 a 40 anos. Grau de instrução dos pais: $30 \%$ possuem ensino médio completo; $22 \%$ ensino fundamental completo; $18 \%$ ensino fundamental incompleto; $14 \%$ ensino superior completo; $8 \%$ ensino superior incompleto; $6 \%$ ensino médio incompleto; $2 \%$ outros.

\section{Utilização do computador e freqüência de uso}

Entre os estudantes universitários entrevistados, 94\% disseram que utilizam computadores e $6 \%$ não responderam à questão.

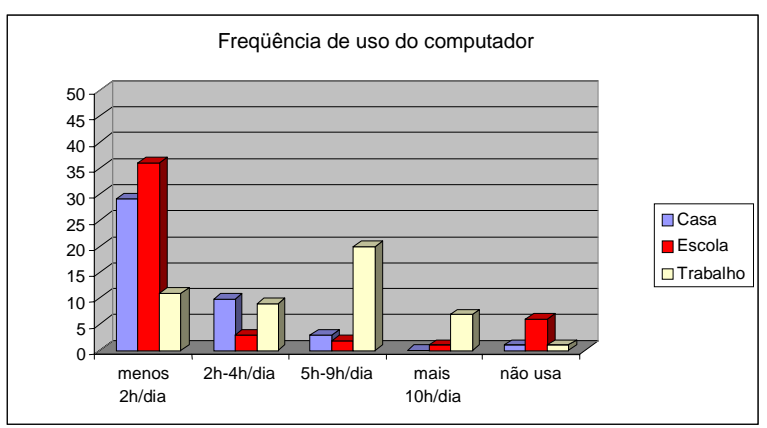

FIGURA 7 - Freqüência de uso do computador

A categoria "uso em casa" teve como maior freqüência a utilização de menos de duas horas por dia, seguido do uso de duas a quatro horas por dia e, em último lugar, o uso de cinco a nove horas por dia. A categoria de "uso na escola" teve como maior freqüência a utilização de menos de duas horas por dia; em seguida o uso de duas a quatro horas por dia. A categoria de "uso no trabalho" teve como maior freqüência a alternativa cinco a nove horas por dia, seguida pelo uso de menos de duas horas por dia; em terceiro lugar o uso de duas a quatro horas por dia e em quarto lugar o uso de mais de dez horas por dia.

\section{Tempo de uso do computador e para que usa}

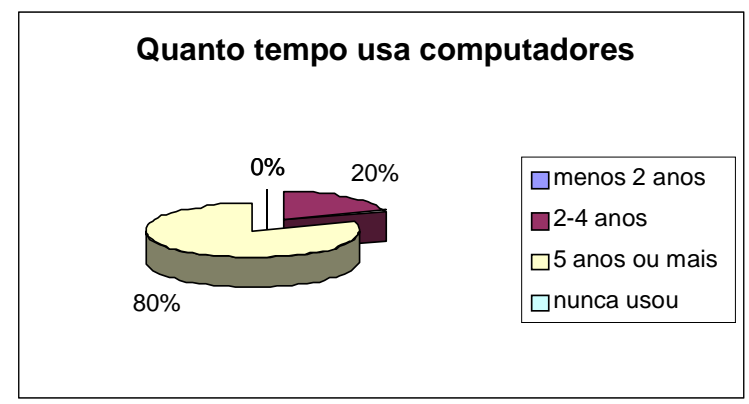

FIGURA 8 - Tempo de uso do computador

Dos estudantes universitários entrevistados, $80 \%$ utilizam o computador há cinco anos ou mais, enquanto que $20 \%$ utilizam há dois a quatro anos.

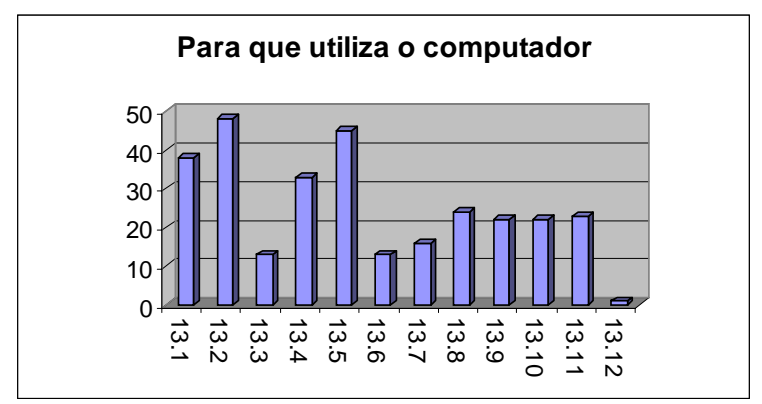

FIGURA 9 - Para que utiliza o computador 
13.1 - Informação (leitura de jornais e revistas)

13.2 - Correio eletrônico (email)

13.3 - Programação

13.4 - Redação/Editoração de textos

13.5 - Pesquisas na Internet

13.6 - Chats (Bate papo)

13.7 - Manutenção de bancos/bases de dados

13.8 - Preparação/manutenção de planilhas eletrônicas

13.9 - Ouvir/gravar músicas

13.10 - Jogos

13.11 - Usuário de sistema especifico

13.12 - Outros

Em relação ao uso do computador, a maior frequiência é o uso do correio eletrônico, em seguida pesquisa na Internet. A informação (leitura de jornais e revistas) aparece em terceiro lugar, seguida de redação/editoração de textos.

\section{Softwares e sistemas operacionais mais utilizados}

Os softwares e sistemas operacionais foram considerados da mesma forma como alternativas de softwares mais utilizados. Assim, o sistema operacional Windows aparece em primeiro lugar seguido respectivamente pelo MS-Word e Internet Explorer.

\section{Os estudantes universitários e o uso da Biblioteca}

Entre os estudantes universitários entrevistados, 90\% utilizam a biblioteca, enquanto $10 \%$ não a utilizam; $88 \%$ disseram que a biblioteca é informatizada, já $12 \%$ disseram que a biblioteca não é informatizada.

A maior frequiência para o uso da biblioteca foi empréstimos de livros, seguida de estudo de conteúdos indicados pelos professores e elaboração de trabalhos. Em quarto lugar aparece a pesquisa na Internet e em quinto lugar a leitura de jornais e revistas. Apesar de $90 \%$ terem conhecimento de que a biblioteca é informatizada, a pesquisa na Internet aparece em quarto lugar. As alternativas: "levantamento de livros no catálogo bibliográfico", "pesquisa em bases de dados especializadas" e "conferir informações na Internet" aparecem com baixa freqüência, o que indica que muitos alunos desconhecem os recursos oferecidos pelas bibliotecas informatizadas.

\section{URBANO VERSUS RURAL}

Para análise Urbano versus Rural, foram utilizados os dados e gráficos referentes às questões $7,8,10,11,12$ e 13 do questionário.

$\mathrm{O}$ primeiro grande contraste entre a área rural com a urbana está relacionado à escolaridade dos pais. A pesquisa na área rural aponta $83 \%$ dos pais com ensino fundamental incompleto e apenas $2 \%$ com superior completo; já na área urbana são $29 \%$ com o ensino fundamental incompleto e $10 \%$ com superior completo.

A escolaridade dos pais, assim como a área onde vivem, influem diretamente no conhecimento e acesso às tecnologias da informação, sendo que no item 8 ("Assinale as Tecnologias da Informação que você conhece"), as únicas tecnologias onde existe alguma igualdade de conhecimento são o rádio, o telefone, o celular e a televisão. Estas tecnologias são bem conhecidas na área rural, por seu uso simplificado e de fácil acesso, exigindo também pouco conhecimento tecnológico de quem as utiliza.

O cinema, o videogame e o computador são tecnologias menos conhecidas na área rural, sendo apontadas por aproximadamente $72 \%$ 
dos pesquisados. Já na área urbana estas tecnologias atingem praticamente $100 \%$ da amostragem. O CD/DVD, o fax e a Internet são tecnologias menos conhecidas pela população rural, ou seja, apenas $1 / 3$ da amostra rural em relação à urbana tem algum conhecimento sobre estas tecnologias.

Quanto ao uso dos computadores, 32\% da amostra rural utiliza essa tecnologia, sendo que destes $32 \%$, 30\% utilizam o computador somente na escola e menos de duas horas por dia, enquanto $93 \%$ da amostra urbana utilizam-na com freqüência na escola, no trabalho e em casa. Podemos notar ainda que quase a totalidade dos alunos da área urbana utilizam regularmente o computador não apenas na escola, mas também em casa e no trabalho.

Dos alunos da escola rural, 94\% nunca usaram computador ou o usam há menos de dois anos. Já 58\% dos alunos da área urbana utilizam o computador há mais de cinco anos.

Percebemos a falta de significado e utilidade do computador enquanto tecnologia de comunicação para os alunos da área rural, pois, ao analisar a questão 13 ("Para que você utiliza computadores?") constatamos que metade dos alunos utiliza o computador para jogos, sendo que o segundo software mais utilizado, com 1/3 dos alunos, é o de processamento de texto. $\mathrm{O}$ significado $\mathrm{e}$ utilização do computador como tecnologia de comunicação são bem mais claros para os alunos da área urbana, os quais diversificam mais os softwares utilizados.

\section{Uso do computador versus pesquisa}

Para a análise do agrupamento Uso do computador versus Pesquisa, foram utilizados os dados e gráficos referentes às questões 13, 15, 16 e 17 do questionário.
Dentre os itens na questão 13 ("Para que você utiliza computadores?"), ("Para que você utiliza computadores?"), os mais relevantes para determinar o uso do computador para a pesquisa através de sistemas informatizados são os itens 13.1 (Informação - leitura de jornais e revistas) e o 13.5 (Pesquisas na Internet), que, somados, indicam que pouco mais de $50 \%$ dos alunos utilizam o computador para algum tipo de pesquisa acadêmica.

Os dados também demostram que $88 \%$ dos alunos utilizam a biblioteca, sendo que a maioria empresta livros, estuda conteúdos indicados pelo professor e elabora trabalhos. Outro item destacado é o baixo uso da biblioteca como fonte de pesquisa em base de dados especializados e Internet. Acreditamos que isso aconteça pela falta de estrutura de duas das três bibliotecas citadas, ou seja, somente uma é informatizada e possui acesso a bases de dados especializadas para pesquisa.

Apesar do aumento da utilização do computador para pesquisa, a biblioteca continua sendo a principal fonte de pesquisa, sendo ela informatizada ou não. É importante ressaltar que na biblioteca informatizada o uso de computadores, juntamente com a Internet e com as bases de dados especializadas, também foram apontados como fontes de pesquisa.

\section{Otimistas versus Pessimistas}

Para a análise do agrupamento Otimistas versus Pessimistas, foram utilizados os dados e gráficos referentes à questão 9 do questionário.

A maioria dos alunos apontou os itens: 9.3 (Globalização da informação); 9.5 (Facilidade de acesso à informação); 9.8 (Disponibilidade da informação "ao vivo" ou "on line"); 9.9 (Acesso rápido à 
informação); 9.15 (Maior comunicação entre as pessoas); 9.17 (Exigência de maior qualificação profissional); 9.20 (Maior acesso ao conhecimento); e 9.22 (Busca de qualificação), como as principais transformações que as tecnologias da informação trouxeram. Todos estes itens traduzem uma visão otimista das tecnologias, tendo como viés principal o acesso à informação e à formação profissional.

Os itens menos apontados foram: 9.2 (Acesso à informação restrita a uma "elite" de pessoas); 9.4 (Controle da informação); 9.6 (Dificuldade de acesso à informação); 9.10 (Banalização da informação); 9.11 (Confiabilidade nas informações); 9.12 (Desqualificação da informação); 9.16 (Menor comunicação entre as pessoas); e 9.18 (Maior solidariedade entre as pessoas). Com exceção dos itens 9.11 e 9.18, o restante tem um viés pessimista.

Diante desta primeira análise, foi possível perceber que os itens 9.13 (Desemprego) e 9.14 (Novos postos de trabalho), ligados ao emprego e ao desemprego, foram apontados de forma bastante ponderada e não se destacaram em relação aos demais. Acreditamos que esse fato pode estar diretamente relacionado ao otimismo anteriormente detectado a respeito das tecnologias da informação.

Os itens mais apontados 9.3 (Globalização da informação), 9.5 (Facilidade de acesso à informação) e 9.9 (Acesso rápido à informação), estão ligados diretamente à facilidade e rapidez de acesso à informação "globalizada", o que nos permite dizer que o público-alvo desta pesquisa conhece a potencialidade das tecnologias da informação como instrumentos de pesquisa e fonte de informações.
O que mais nos surpreendeu, neste tópico da análise, foi o otimismo em relação às tecnologias da informação, pois inicialmente pensávamos que questões como desemprego, desqualificação da informação e "elitização" da informação fossem ser mais indicadas e polemizadas.

\section{Software versus Utilização}

Para análise do agrupamento Software versus Utilização, foram utilizados os dados e gráficos referentes à questão 14 do questionário. Essa análise demonstrou que softwares como Visual Basic, Delphi, MSFrontPage, programas gráficos e de engenharia são apontados normalmente pelos alunos do ensino técnico e do ensino universitário como mais utilizados, naturalmente em decorrência da área de profissionalização.

Os softwares considerados de "uso livre" Linux e Netscape foram pouco apontados, O mesmo não acontece com seus correspondentes, Windows e Internet Explorer, lembrados pela maioria dos alunos. A baixa consideração das unidades de ensino em relação aos softwares "livres" demonstra o desconhecimento ou o pequeno interesse na utilização destes produtos.

Os softwares utilizados para o lazer, como jogos, ICQ e MP3 players, foram apontados de forma bastante modesta, o que nos espantou, pois nossa expectativa era maior em relação a este grupo.

Observamos a maior frequiência de uso de softwares comerciais líderes no mercado brasileiro (principalmente os da Microsoft) não gratuitos, como, por exemplo, o MSOffice. Não podemos afirmar, mas achamos que isso ocorre não por escolha do usuário e sim por "imposição do mercado" e de diversas instituições de ensino. 


\section{O QUE É INFORMAÇÃO PARA VOCÊ?}

A pergunta aberta 19 ("O que significa informação para você?") foi respondida por 135 estudantes; dos quais 47 apontaram que informação significa conhecimento.

Informação como poder também merece destaque, como na seguinte resposta: "Vital, com ela você ganha uma guerra”.

Alguns estudantes responderam apenas que informação é cultura.

Ressaltamos as seguintes colocações que também podemos incluir em respostas relativas à cultura de uma forma geral:

"Informação nada mais é do que sinônimo de crescimento pessoal, profissional, mas acima de tudo, de cultura humana." ou na resposta que relaciona informação a cultura na sociedade, ou seja, aprendemos a cultura através da informação:

"Informação para mim é tudo, não importa o modo em que chega até mim, pois quando nascemos não sabemos nada, precisando desde cedo coletar informações, mas é necessário pelo menos ser crítico com as informações".

Mereceram nossa atenção também respostas que relacionam a informação à vida: "Evolução do ser humano", "Viver em sociedade" ou simplesmente "Viver".

A relação entre informação, qualificação e mercado profissional não mereceu muito destaque dos alunos; exemplificamos com a seguinte resposta: "O caminho mais fácil de se chegar aos acontecimentos que nos rodeiam, e também de interesse profissional”.

Assim como conhecimento, muitos alunos usaram a expressão: "tudo" para explicar o que é informação. Como exemplo, esta resposta relaciona o "tudo" com o mundo globalizado: "Tudo (é o bem mais valioso no mundo globalizado)." e também o "tudo" sob um outro ângulo, ou seja: "Tudo o que é dito sobre alguma coisa é uma informação”.

A informação como sinônimo de informática pode ser observado nas seguintes respostas: "A informação é o coração da informática, tudo que foi criado na informática é para se obter a informação, guardar, modificar, transportar, consultar e proteger" e ainda informação como "dados", na seguinte resposta: "Para mim, informação significa ter ou obter dados sobre um determinado assunto ou tema; a informação é como uma bula de remédio que passa dados, explicando e precavendo as pessoas ligadas ao assunto, e interessados." ou a resposta do internauta que não navega, mas "voa": "Um meio de se comunicar e 'voar' na Internet”.

Mas se a informação se relaciona com a informática para os estudantes acima, para alguns há uma "equivalência semântica", como podemos observar nas três respostas abaixo em que alguns estudantes confundem a palavra "informatizado" como sinônimo de "informado":

"Ficar mais informatizada sobre as coisas que acontecem nos dias de hoje";

"Conhecimento, amplitude de dados e se manter informatizado no que ocorre no mundo";

"Significa ficar informatizado do que acontece no mundo".

Um grupo significativo de estudantes relacionou informação com a mídia, com os meios de comunicação, como podemos observar: "É ficar informada de tudo o que acontece e saber das notícias que passam no jornal e nos programas de TV' ou ainda: "Significa mensagem". 
Destacamos, por último, a informação ligada à velocidade e à rapidez das transformações no mundo das tecnologias, como nesta resposta: "Estar atualizado no que acontece no mundo, já que a informação é renovada em poucos segundos.” $E$ finalizamos com a resposta que representa a vertigem dos acontecimentos ligados à revolução das tecnologias da informação: "Uma coisa nova, uma coisa urgente”.

\section{CONSIDERAÇÕES FINAIS}

Não é possível falar em Sociedade da Informação e TIC sem se referir à democratização da informação e da educação.

Os estudantes apresentaram uma expectativa bastante otimista em relação às mudanças sociais provocadas pelas TIC. No entanto, a análise dos dados nos mostrou que, se de um lado há nos estudantes uma expectativa otimista e uma abertura para assimilar as transformações, temos, de outro lado, uma realidade social e econômica que os separam.

$\mathrm{O}$ acesso aos computadores no trabalho, em casa e na escola, e ao universo midiático de comunicações, como um todo, está restrito a um grupo de estudantes. Os alunos da escola rural estão excluídos do acesso à Internet, restringindo seu universo de comunicação.

A tecnologia se tornou um atributo indispensável para o marketing educacional. Apesar disso, entendemos que o acesso à informação não deve ser apenas meio e muito menos um fim em si mesmo. Concluímos que as TIC são parte da cultura e, como todos os bens culturais, devem ser democratizadas.

Verificamos com otimismo o uso das bibliotecas pelos estudantes das três escolas, porque $\mathrm{o}$ acesso à informação não deve restringir-se ao uso de tecnologia de informação e comunicação. $O$ acesso à educação fundamental antecede a capacitação para o uso criativo e autônomo das TIC.

\section{REFERÊNCIAS}

AVEDON, Don M. GED de A a Z: tudo sobre gerenciamento eletrônico de documentos. São Paulo: CENADEM, 1999.

BRENANND, Edna G. de G. Uma nova política de civilização: a sociedade informacional. In. AQUINO, Míriam de Albuquerque. (org.). O Campo da ciência da Informação: gênese, conexões e especificidades. João Pessoa: Universitária, 2002.

CASTELLS, Manuel. A sociedade em rede. São Paulo: Paz e Terra, 2000.

CRUZ, Tadeu. Workflow: a tecnologia que vai revolucionar processos. São Paulo: Atlas, 1998.

LÉVY, Pierre. Cibercultura. São Paulo: Ed. 34, 1999.

POSTMAN, Neil. Tecnopólio: a rendição da cultura à tecnologia. São Paulo: Nobel, 1994.

RUBEN, Guilhermo; DWYER, Tom; WAINER, Jacques (Org.). Informática, organizações e sociedade no Brasil. São Paulo: Cortez, 2003.

TAKAHASHI, Tadao (org.). Sociedade da Informação no Brasil: livro verde. Brasília: Ministério da Ciência e da Tecnologia, 2000.

WALDMAN, Hélio, YACIOUB, Michel D. Telecomunicações: princípios e tendências. São Paulo: Érica, 2000. 


\section{Agradecimentos}

Agradecemos aos professores da UUNICAMP: Guilhermo Ruben, Tom Dwyer e Jacques Wainer organizadores da disciplina Sociedade da Informação: uma análise multidisciplinar, pelas orientações críticas durante a pesquisa e a Flávio Faria pela coleta de dados na escola rural.

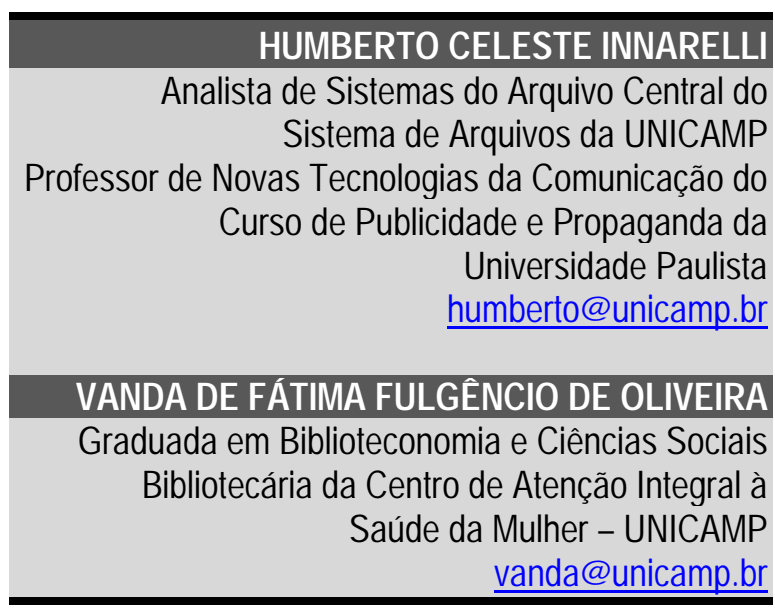

Aceito para publicação em: 30/11/2003 